\title{
O ensino e a saúde: um olhar biológico
}

\author{
Teaching and health: a biological view
}

Nelson Vaz 1

\footnotetext{
1 Departamento de Bioquímica e Imunologia, ICB, Universidade Federal de Minas Gerais. Av. Alfredo Balena 190, Belo Horizonte, MG 30130-100, Brasil. nvaz@mono.icb.ufmg.br
}

\begin{abstract}
A bstract Living systems are structure determi ned systems. Teaching is never feasible, but learning is inevitable, a comment by an observer about some aspect of the constant changes occu rring while life goes on. Teachers are all those who open up spaces for conviviality and allow congruent changes to take place. There are no instructive interactions in nature. Health and the biology of living systems are phenomena studied in different domains. What is healthy or unheal thy for humans, is defined by human culture. As biological phenomena, health and diseaseare relational configurations of the organism and its medium. From this perspective, individual health is a social phenomenon.

Key words Health Education; Epistemology; Education; Health

Resumo Os seres vivos são sistemas determinados por suas estruturas. O ensino é impossível, mas a aprendizagem é i nevitável, um comentário de um observador sobre al gum aspecto das mudanças constantes que ocorrem durante o viver. Professor é aqu el e que abre um espaço de convivência. Não existem interações instrutivas na natureza. A saúdee a biol ogia dos seres vivos são fenômenos estudados em domínios distintos, a primeira sendo definida pela cultura. Como um fenômeno biológico, a saúde ou a doença são configurações relaci onais do organismo com seu meio e, como tais, são fenômenos descritos no domínio das i nterações do organismo. Por esse entendimento, a saúde individual é um fenômeno social.

Palavras-chave Educação em Saúde; Epistemologia; Educação;Saúde
\end{abstract}


Introdução

$\mathrm{Na}$ imunologia, predominam interesses biomédicos, mas gosto de pensar em meu trabalho como biológico, e nosso laboratório na Universidade Federal de Minas Gerais se chama laboratório de imunobiologia. Ao discutir o ensino de temas relativos à saúde, não vou me referir a vacinas, como seria esperado. Vou abordar temas mais gerais. Quero convidá-los a refletirmos juntos sobre:

1) a biologia do ensino;

2) saúde e biologia.

\section{1) A biologia do ensino}

Parece estranho falar da biologia do ensino. É natural que biólogos estejam acostumados a estudar as relações entre biologia e aprendizagem; a adaptação e a evolução são exemplos notáveis. Na imunologia, a aprendizagem é um assunto natural, pois, na imunização, o organismo parece lidar com novidades moleculares; por exemplo, aprende a lidar mais eficazmente com germes e vírus. A imunização pode ser vista como uma forma celular/molecular de aprendizagem. Muitos imunologistas designam as respostas imunes específicas como 'imunidade adaptativa'. É fácil também estabelecer paralelos entre a aprendizagem e outros fenômenos biológicos.

Aqui há uma bifurcação importante, cujo significado não devemos menosprezar. O que dizer sobre o ensino? Alguém, ou al go, 'ensina' os organismos em suas modificações evolutivas? Existe algum sentido em afirmar que o antígeno 'ensina' o organismo a responder imunologicamente? Por acaso a vacina contra a poliomielite 'ensina' uma lição molecular, dá uma aula ao organismo das crianças, que as torna vacinadas, un iformemente mais resistentes à poliomielite?

O que aprendemos sobre a organização e a estrutura dos seres vivos nos últimos cinqüenta anos nos obriga a responder a essas perguntas com um enfático não. Na biologia, como no resto da natureza, não ocorrem interações instrutivas. Os seres vivos não podem ser vergados em direções arbitrárias, ditadas por suas interações com o ambiente. Isso parece contraditório porque as primeiras soluções sugeridas para problemas biológicos tendem a ser instrutivas (Jerne, 1967). Bactérias são expostas à penicilina e surgem variedades resistentes; pintase de branco a parede da fábrica e as borboletas sobre elas se tornam mais claras; um coeIho é injetado com hemácias de carneiro elogo surgem anticorpos específicos. Tudo se passa como se a penicilina ensinasse as bactérias a serem resistentes; o branco da parede ensinasse às borboletas a mudar de cor; e o antígeno, as hemácias, guiasse a formação dos anticorpos. Depois surgem as explicações seletivas: a cultura de bactérias já incluía mutantes resistentes à penicilina; a população de borboletas já incluía indivíduos mais claros; o coelho já produzia anticorpos anti-hemácias em pequena quantidade - a exposição às hemácias apenas favoreceu a sobrevivência de célul as que os produziam. Em todos esses casos, tudo se passa como se um elemento externo ao sistema interagisse com elementos do sistema e os favorecesse. Esta é a metáfora em que Darwin se apoiou na Teoria de Seleção Natural (Darwin, 1979), para explicar a origem das espécies, pois tudo se passa como se a natureza selecionasse os indivíduos mais aptos, ou de maior eficiência reprodutiva (Young, 1985).

Assim, embora possamos atribuir certas mudanças nas características dos seres vivos a uma aprendizagem, esta não decorre de alguma forma de ensino, mas sim como da própria estrutura dos seres vivos. Elas dependem do desenrolar de seqüências de mudanças estruturais desencadeadas por um pareamento de interações do ser vivo em seu ambiente com a dinâmica estrutural própria do ser vivo. Os seres vivos são sistemas determinados por sua estrutura (Magro et al., 1997; Maturana \& Varela, 1980; Maturana, 1988).

Estamos acostumados a encarar o ensino e a aprendizagem como duas faces da mesma moeda, porém o que propomos aqui é radicalmente diferente. Estamos propondo que não existe instrução (ensino), mas a aprendizagem é inevitável. Aprender é um fenômeno trivial, constitutivo dos seres vivos, que ocorre incessantemente em virtude da sua dinâmica interna e pelas interações incessantes que ele realiza em seu ambiente.

$\mathrm{Na}$ concepção usual, as interações com o ambiente são encaradas como estímulos eas mudanças ocasionadas nos seres vivos vistas como respostas. Na imunologia, por exemplo, é possível falar de estímulos antigênicos e respostas imunes específicas. Os estímulos antigênicos, porém, não ensinam ao organismo como responder. Para constituir um estímulo antigênico, o material deve encontrar no organismo uma coleção pré-formada de estruturas moleculares nas quais possa se encaixar com energia suficiente. As moléculas e células que funcionam como se fossem receptores específicos já estão presentes no organismo antes do contato com o material antigênico. Podemos 
optar por ver tais moléculas e células como dotadas da função (ou propósito) de reagir com o antígeno; entretanto, elas são componentes do organismo que só persistem enquanto mantêm relações com outros componentes do organismo. As noções de estímulos antigênicos e respostas imunes específicas desaparecem em uma linguagem que descreva o organismo em termos de sua conectividade interna. Mas, enveredar pela imunologia não é minha intenção aqui. Retomemos, portanto, a questão inicial .

Em uma abordagem celular/ molecular dos fenômenos biológi cos, vemos o ensino como uma noção imprópria, enquanto a aprendizagem é vista como um fenômeno incessante, decorrente da dinâmica estrutural dos seres vivos. Todavia, como transportar isso para a sala de aula? Afinal, se não existe ensino, o que é uma aula? O que é um texto didático?

\section{A aprendizagem como um comentário}

De acordo com Maturana \& Varela (1980), os alunos são sistemas determinados por sua estrutura e as interações instrutivas são biologicamente impossíveis. Mas, se o professor não está ensinando a seus alunos, como podemos entender o que ocorre em uma aula, ou em uma seqüência de aulas? Como negar que o ensino ocorre se o professor comprova, por meio de perguntas e outras formas de avaliação, que a aprendizagem ocorreu? É verdade que alunos diferentes sofrem mudanças diferentes no decorrer da convivência com o professor, mas todos, ao seu modo, parecem aprender alguma coisa.

Que os al unos mudem durante a convivência e que cada um ten ha seu modo de mudar não é surpreendente, nem pode ser usado como argumento para demonstrar que o ensino ocorreu. Estamos propondo que a aprendizagem, como uma forma de mudança atribuída por alguém a um outro alguém (o aprendiz), é uma decorrência inevitável do existir em convivência. Como seres vivos que somos, estamos em contínua mudança. Tais mudanças ocorrem, em parte, como decorrência de nossa própria dinâmica interna; em parte, por interações com elementos de nosso ambiente. As pessoas com as quais convivemos são elementos muito importantes nas mudanças que atravessamos como seres humanos. Na verdade, se esta convivência não se estabelecesse nos períodos precoces de nossa existência, não sobreviveríamos e, se o fizéssemos, não adquiriríamos características típicas de nossa espécie, como a capacidade de andar ereto em dois pés, a mímica facial, ou a fala.
Grande parte do desenvol vimento do comportamento de aves e mamíferos depende de condutas recursivas e recíprocas realizadas com o auxílio e/ou na companhia de outros animais da mesma espécie - a mãe, pai, irmãos, membros de uma comunidade. A corte sexual em muitas espécies de aves e peixes constitui um bom exemplo de padrões de interações recíprocas. Maturana se refere aos comportamentos que ocorrem em domínios consensuais, como estes, de comportamentos lingüísticos.

A linguagem humana constitui um claro exemplo de comportamento lingüístico, mas Maturana inclui qual quer domínio de interações gerado mutuamente pelos participantes como linguagem. A linguagem, encarada como um domínio consensual, é uma padronização de comportamentos que, mutuamente, orientam-se. Uma coordenação de ações, e não uma transmissão de informações, como usualmente a interpretamos.

Em nossa interpretação habitual, fazemos uso do que Reddy chamou “a metáfora do tubo" (Reddy, 1979). Imaginamos que comunicação é al go gerado em um ponto (emissor), conduzido por um 'tubo', e entregue a outro ponto (receptor). Dessa forma, existe algo que se comunica, que se desloca pelo tubo. Segundo Maturana \& Varela (1980), essa imagem é falsa, pois pressupõe uma interação instrutiva. O fenômeno da comunicação não depende do que se entrega e sim do que se passa na coordenação da conduta. Isso é muito diferente da idéia de transmitir informações.

Para um observador dessa coordenação de condutas, porém, tudo se passa como se ocorresse a transmissão de informações. Estamos acostumados a pensar que palavras e frases se referem a objetos e coisas que existem independentemente de nós. De acordo com Maturana (1993), como seres biológi cos que somos, não podemos conhecer uma realidade externa. Temos uma estrutura que reflete uma história de interações com o meio, tanto recente (ontogenia), como remota (filogenia), mas o meio não é composto de coisas conhecíveis. Quando falamos de um mundo, estamos agindo como observadores deste mundo e fazendo distinções em um domínio consensual.

Um dos aforismos centrais na perspectiva descrita por Maturana \& Varela (1980:13) é: "Tudo édito por um observador a outro observador, que podeser ele mesmo."

A idéia de distinções geradas pelo observador não foi criada por Maturana. Na psicologia da Gelstat, por exemplo, Kohler (1925) argumentava que todos os eventos perceptivos são 
internos ao observador. Maturana propõe a idéia de domínios consensuais, de algum tipo de interação social na qual o observador está, necessariamente, envolvido. Este autor não afirma que nosso discurso se refere somente a eventos internos, como pensamentos e sentimentos (o que constituiria uma posição solipsista), mas sim que todos os discursos existem em um domínio consensual (um domínio de coordenação de ações entre organismos). Para Maturana, a realidade não é nem objetiva, nem individual. A atividade tipicamente humana, o linguajar, é uma atividade coletiva.

\section{Quem é o professor?}

Se não estamos transmitindo informações simbólicas ao nossos aprendizes - porque esta transmissão é impossível e não ocorrem interações instrutivas - , as modificações de conduta que eles atravessam em sua convivência conosco dependem deste conviver, deste viver juntos. Nesse novo contexto, quem é o professor? Para responder a essa pergunta, transcrevo literal mente um trecho de uma aula de Maturana, em Santiago:

(...)

- Alguma outra pergunta?

- Sim, Professor: Que é um professor? Ou, quem éum professor?

- Humm

(Pausa, risos)

(Escreve ao quadro negro: "Professor, Mestre".)

- E, portanto, está aqui : ensi nar. Creio que aqui aparece este conceito. O queé ensinar? Eu Ihes ensinei a Biologia do Conhecer? Sim, sealguém abre a porta desta sala...

(Desloca-se até a porta, simula ouvir alguém que bate à porta e, então, desculpa-se a alguém que diz em voz baixa a outro alguém fictício: “Nesta sal a está o Professor Humberto Maturana ensinando Bi ologia do Conhecer". Deslocase de volta.)

- Eu Ihes ensi nei a Biologia do Conhecer? Em um senti do, com relação à responsabilidade perantea Faculdade, eu Ihes ensi nei a Biologia do Conhecer.

(Risos)

- Maso quefizemos nós ao longo destesemestre?

- Desencadear mudanças estruturais.

- Desencadear mudanças estruturais,desencadear perturbações. Estupendo! E como fizemosisso?

- Em coordenações de coordenações de ações.

- Em coordenações de coordenações deações. Ou,seja: vivendo juntos. Claro, uma vez por se- mana,viver juntosuma hora, uma hora e meia, duas horas,ou, al guns estudantes, que permaneceram comigo mais horas... I sso era viver j untos. Vocês podem dizer:"Si m, mas eu estava sentado escutando". Isso se estavam verdadeiramente escutando, como espero.

(Risos)

- Estavam sendo tocados, al egrados, entristeci dos,enrai veci dos... Quer dizer, se passaram todas as coisas do viver cotidiano. Mexeram com as idéias, rejeitaram al gumas. Saíram daqui conversando isto emais aquilo..."Estou fazendo um trabalho....". Estavam imersos na pergunta: "Como prosseguir de acordo com o que Ihes ia passando, vivendo juntos, comigo, em um espaço que se ia criando comigo". Então, qual foi a minha tarefa? Criar um espaço de convivência. Isto é ensinar.

(Escreve ao quadro: Criar um espaço deconvivência.)

- Bem, eu ensinei a vocês. E vocês, ensinaram a mim?

- Sim.

- Claro quesim! Ensinamo-nos mutuamente. "Ah, mas acontece que eu tinha a responsabili dade do curso, e ia gui ando o que acontecia". Decerta forma, sim, de certa forma, não. Decerta forma, sim, porque há certas coisas que eu entendo da responsabilidade e do espaço no qual memovo nesta convivência, etinha uma certa ori entação, um fi o condutor, um certo propósito. Mas vocês, com suas perguntas, foram empurrando esta coisa para lá, e para cá, e foram criando algo que foi se configurando como nosso espaço de convivência.

E o maravilhoso de tudo isso é que vocês aceitaram que eu me aplicasseem criar um espaço de convivência com vocês. Vocês se dão conta do significado disso? Foi exatamente igual ao que ocorreu quando vocês chegaram, como crianças, ao jardim de infância, e estavam tristes, emburrado; a mamãe se foi, estão chorando, "Aaahh, eu quero minha mãe". Chega a professora, oferece a mão, e vocês a recusam, mas ela insiste, então, vocês pegam sua mão. E o que se passa quando a criança pega na mão da professora? Aceita um espaço de convivência.

Com vocês se passou a mesma coisa. Em algum momento, aceitaram minha mão. $E$, no momento em que aceitaram minha mão, passamos a ser co-ensinantes. Passamos a participar juntosn este espaço de convi vên dia. E nos transformamos, em congruência... Demaneiras diferentes,porque,claro, temos vidas diferentes,temos diferentes espaços de perguntas, temos experiências distintas. Mas nos transformamos juntos, eagora podemos ter conversas que antes não podíamos. 
E quem é o professor? Al guém que se aceita como guia na criação deste espaço de convivência. No momento em que eu digo a vocês:" Perguntem", e acei to que vocês me guiem com suas perguntas, eu estou acei tando vocês como professores, no senti do de que vocês me estão mostran do espaços de reflexão ondeeu devo ir.

Assim, o professor, ou professora, é uma pessoa que deseja esta responsabilidade de criar um espaço deconvivência, este domínio de aceitação recíproca que se configura no momento em que surge o professor em rel ação com seus alunos, e se produz uma dinâmica na qual vão mudando juntos."

\section{Realidade}

Maturana é um pensador radical. Ele insiste em que o problema da realidade é o mais importante enfrentado pela humanidade hoje em dia, tanto para as pessoas que estão conscientes disso, quanto para as que não estão, porque tudo o que fazemos como indivíduos ou como sociedades depende de, apóia-se na noção que temos sobre a realidade (Magro et al., 1997; Maturana, 1988).

Eis aqui um de seus parágrafos iniciais:

“Na verdade, eu afirmo que a resposta implícita ou explícita que cada um de nós dá à questão da Real i dade determina como el e ou ela vi ve sua vida, assi $m$ como sua aceitação ou rejeição de outros seres humanos na rede desistemas sociais e não-sociai s que el e ou ela integra. E, finalmente, desde que nós sabemos pela vida diária que o observador é um sistema vivo porque sua competência cognitiva éalterada se sua biologia é alterada, eu afirmo que não é possível ter uma compreensão adequada dosfenômenos sociais enão-sociais na vida humana se essa questão não é propriamente respondida, e que esta questão pode ser propriamente respondida somente se o observar ea cognição forem explicados como fenômenos bi ológi cos gerados através da operação do observador como um ser humano" (Maturana, 1988:25).

\section{Saúde e biologia}

O modo de olhar e as conversações que guiam esse olhar configuram o que se vê e o que se faz. Não apenas isso: o modo de olhar configura as perguntas aceitas como importantes (Maturana, 1993). No modo de olhar usual na imunologia, os fenômenos imunológicos surgem ligados à saúde, isto é, à proteção do corpo contra a invasão por materiais estranhos, princi- palmente os de germes, vírus e parasitas. No modo de olhar que propomos para a imunobiologia, os fenômenos imunológicos surgem como fenômenos biológicos e não como fenômenos ligados à saúde. Na visão habitual, essa última frase não faz sentido, porque os fenômenos ligados à saúde são vistos como fenômenos biológicos, por exemplo, como fenômenos ligados à vida dos micróbios e à resistência dos seres humanos a infecções. Mas a saúde e o viver podem também ser vistos de outro modo. Quero explicitar isso melhor.

O que constitui a saúde, ou o que é desejável no viver, é um fenômeno cultural. Na Coréia, a carne de cães é parte de pratos tradicionais. Comer o fígado e os intestinos de um leãomarinho recém-abatido, ainda quentes, com seu conteúdo incluindo vermes, parece-nos um costume abominável. Para os esquimós, é uma conduta essencial à sobrevivência em um ambiente onde vitaminas são pouco acessíveis. Em muitas culturas, o corpo humano é deliberadamente modificado, cortado, esticado de maneiras que nos parecem mutilações ou deformações. Para membros de outras culturas, o físico flácido e obeso comum em nossa vida sedentária de 'civilizados' é visto como deformado. A dieta do homem 'civilizado' gera cáries dentárias e doenças metabólicas ausentes em outras culturas.

Por outro lado, "O que consti tui o vi ver?" e "Qual a organização dos seres vivos?" são perguntas adequadas à investigação biológica atual. Digo isso no sentido literal , pois já existem propostas bastante claras para respondêlas. Já foram descritos mecanismos capazes de gerar e diversificar o enorme número de linhagens dos seres vivos que surgiram na história do planeta. Esses são os mesmos mecanismos de autogeração que mantêm vivendo os seres vivos atuais. Nesse modo de ver, já sabemos como se constituem os seres vivos e podemos ser mais explícitos sobre isso.

Ao descrever os seres vivos, Maturana também descreve a nós, seres humanos e nossa origem, como observadores operando na linguagem. Aceitar o que constitui as explicações em geral e as explicações científicas, em particular, é essencial para aceitar o que constitui o viver e o que são os seres vivos. Portanto, não posso partir de premissas tacitamente aceitas. Quando falo do viver, não falo da saúde, embora a história do viver através dos tempos tenha sido a história dos seres saudáveis.

No modo de olhar característico da imunologia, os fenômenos imunológicos surgem como fenômenos ligados à saúde, isto é, à proteção do corpo contra a invasão por materiais es- 
tranhos. Concordo com Maturana quando ele afirma que, em seu viver, os seres vivos não têm saúde, nem doença. Podemos ver os fenômenos imunológicos como fenômenos próprios do viver, parte da operacionalidade constitutiva do organismo. Nesse modo de olhar, a saúde surge como uma preocupação indireta, embora importante.

Como um fenômeno cultural, a saúde deixa de ser um atributo do organismo e passa a ser uma configuração relacional organismo/meio, um fenômeno descrito no domínio das interações do organismo. Por esse entendimento, a saúde individual é um fenômeno social. Na definição proposta pela Organização Mundial de Saúde (OMS), a saúde é definida pela ausência de doença ou de desconforto psíquico. Mas interdefinir a saúde e a doença não adianta muito. Definir o que falta quando se perde a saúde importa menos que a descrição de mecanismos capazes de gerar e manter a saúde da população e conter o abuso social. Mesmo argumentos imunológicos podem ser usados politicamente. Meu colega imunologista Tomaz Mota Santos, hoje reitor da UFMG, dizia que "com as campanhas devacinação, os governos querem que o corpo resol va nossas contradi ções sociais". Para Virchow, "sea doença éuma conseqüência do desequilíbrio indivi dual, então, as epidemias su rgem em soci edades desequili bradas".

Uma rápida consulta ao The Cambridge World History of Human Di sease (Kiple, 1993), uma alentada coleção de 1.200 páginas, mostra que, durante a história da humanidade, as doenças infecciosas estiveram mais associadas a fenômenos sociais, como desastres agrícolas, guerras, grandes migrações etc., do que aos fenômenos sobre os quais a imunologia pode influir. A peste que atingiu a Europa no século XIII, por exemplo, surgiu após dois anos de chuvas quase ininterruptas. As doenças infecciosas não foram um fator importante na evolução dos seres humanos ou de qualquer outro animal (Mckeow, 1988). Essa é uma afirmação difícil de aceitar em uma época como a nossa, quando parecem ressurgir ameaças de pestilências que acreditávamos haver superado.

\section{U ma mudança de perspectiva}

Quando propomos ol har os fenômenos imunológicos como fenômenos biológicos e não como ligados à saúde, propomos uma mudança não trivial, poisisso tem duas conseqüências (Maturana, 1993):

1) Muda toda a imunologia, uma vez que mudam os fenômenos que a constituem: já não se trata de uma luta do organismo contra agentes externos, e sim de uma visão de interações do organismo consigo mesmo e com componentes de seu ambiente.

2) Amplia-se a visão sistêmica do organismo: o espaço interno se transforma em uma dinâmica relacional molecular/ celular fechada, uma dinâmica que participa da definição do organismo, em vez de ser definida por ele.

Em outras palavras, desaparecem as noções de ataque e defesa. O organismo deixa de estar em oposição a um ambiente que o ameaça, e passamos a ver a dinâmica que integra o organismo e seu meio. Segundo Maturana (1993), o meio em que o organismo opera surge em nossas distinções quan do distinguimos o organismo, no mesmo ato de distinção. Deixando de ver o meio como um agressor, como algo externo ao organismo, podemos vê-lo como o âmbito que torna o organismo possível.

Nesse entendimento, assim como o meio externo, também o meio interno recupera seu caráter dinâmico relacional. O organismo deixa de ser um agregado de células, órgãos e funções e passa a ser uma rede de relações de produções celulares e moleculares que surge como uma totalidade na real ização dessa dinâmica no ambiente em que fica definido como tal organismo. Ao mesmo tempo, o organismo é o âmbito onde surgem muitas outras redes de relações de produções celulares e moleculares, que se entrecruzam com o organismo em sua realização como tal. Essas outras redes - como o sistema nervoso, o sistema endócrino, o sistema hemopoiético, ou o sistema imune - constituem-se como unidades em outros domínios de descrição. Discutiremos como esses diferentes sistemas se entrecruzam no organismo e como eles se mantêm fechados em sua organização.

Vendo o meio como o âmbito que torna o organismo possível, a alimentação - a ingestão de alimentos - passa a ter uma grande influência na atividade imunológica deste, como a forma mais importante e cotidiana de contato com proteínas e, portanto, de interferências do ambiente do organismo sobre a atividade imunológica. Ao alimentar-se, o organismo contata uma enorme variedade de macromoléculas sintetizadas por outros organismos. A mucosa intestinal é duzentas vezes maior que a pele e, além disso, abriga até $90 \%$ das células secretoras de imunoglobulinas do organismo. Muitas moléculas dos alimentos ingeridos são absorvidas intactas ou incompletamente degradadas, e a ati vação linfocitária também envolve uma etapa de degradação (processamento) de proteínas, semel hante a uma digestão parcial no meio intracelular. 
Por esses motivos, consideramos a alimentação como de grande relevância para a atividade imunológica e capaz de influenciar todos os fenômenos imunológicos, não apenas por uma perspectiva nutricional, mas também em relação a interferências que o contato com proteínas no tubo digestivo possam ter sobre a atividade imunológica e, indiretamente, sobre todo o organismo.

A imunologia atual é uma abordagem 'de baixo para cima' (bottom-up)

Diferentemente da genética e da fisiologia, que nasceram do estudo de plantas e animais, a imunologia nasceu associada com a medicina e a bacteriologia médica. Foi a primeira forma bem sucedida de biotecnologia e, de certa forma, isso é o que ela ainda é, embora não tão bem sucedida quanto antes. O objetivo original de produzir novas vacinas fal hou quase totalmente. Exceto por algumas vacinas antivirais produzidas nos aos 50-60, quando os métodos de cultura de tecidos foram desenvolvidos, virtualmente nenhuma vacina importante foi produzida desde o período fundador, a despeito de grandes esforços e dispêndios em pesquisa. Exceções seriam as vacinas para hepatite-B e para H.influenza. A busca de novas vacinas, apesar de muitas inovações (Dickler \& Collier, 1996), permanece um processo, basicamente, empírico.

A grande transformação da imunologia moderna reside, exatamente, na definição de componentes celulares e moleculares envolvidos na atividade imunológica, uma realização mais pertinente à ciência que à tecnologia. A dificuldade atual encontra-se em aplicar esse enorme corpo de conhecimentos biológicos (bioquímicos, genéticos etc.) especializados à medicina. Esse é um problema geral, não particular à imunologia, mas nesta ele assume características especiais.

Movimentadas por um dilúvio de dados sobre componentes celulares e moleculares, as ciências biológi cas contemporâneas também se preocupam em organizar esse conhecimento em quadros coerentes sobre a operação de órgãos, sistemas de órgãos e do organismo como um todo. Na neurobiologia, por exemplo, os conhecimentos celulares e moleculares sobre o cérebro precisam ser correlacionados com conhecimentos sobre a cognição e a conduta do organismo como um todo. Para estabelecer essas correlações, duas tendências são identificáveis: top-down (de cima para baixo) e bottom-up (de baixo para cima): top-down: descubra o que o cérebro/mente faz $\rightarrow$ descubra como implementar tais funções; bottom-up: descubra quais são os componentes $\rightarrow$ descubra o que grandes coleções de tais componentes podem fazer.

Na neurobiologia, a abordagem top-down tem estado presente, como exemplificado pelos títulos dos trabalhos de um dos mais famosos neurobiólogos dos anos 50-60, Waren McCulloch (MacCulloch \& Pitts, 1965; MacCulloch, 1965). A abordagem bottom-up, por sua vez, vem ganhando um prestígio crescente, principalmente por sua associação com a informática e a 'inteligência artificial', sendo atualmente designada computational neuroscience, como mostram alguns de seus títulos importantes (Churchland \& Sejnowsky, 1988, 1992).

Na imunologia, por motivos históricos, a abordagem bottom-up tem sido dominante. Desde a invenção da noção de anticorpos específicos (Von Behring \& Kitasato, 1961), a tarefa dos imunologistas tem sido:

1) elucidar a natureza bioquímica dos antígenos e anticorpos;

2) inventar esquemas eficazes de imunização contra doenças infecciosas (inventar esquemas eficazes de induzir a produção de anticorpos).

Inicialmente, as doenças infecciosas foram entendidas como um duelo entre toxinas microbianas e anticorpos neutralizantes (antitoxinas) ou facilitadores da fagocitose (opsoninas). Somente nos anos 60 , foram identificadas as células (plasmócitos) responsáveis pela produção desses anticorpos. A imunologia celular daquela década, como a de hoje, tinha como preocupação fundamental a elucidação dos mecanismos de formação dos anticorpos. Uma abordagem top-down nunca tevelugar na imunologia, na qual as preocupações mais gerais, como as propostas de articular os componentes celulares e moleculares em um só sistema dotado de propriedades globais não foram comuns. Virtualmente, todas as teorias partiram das propriedades de moléculas, como anticorpos, ou células, como linfócitos.

Mais recentemente, a imunologia sofreu uma grande transformação por associar-se a ramos da bioquímica, como a genética molecular e a biologia celular. Isso teve dois resultados: por um lado, os componentes celulares e moleculares têm se multiplicado em ritmo vertiginoso; por outro, foram caracterizados alguns mecanismos fundamentais da atividade imunológica, como o processamento/ apresentação de peptídeos e as conexões idiotipo/ anti-idiotipo. 
Todo esse conhecimento, no entanto, tem sido incapaz de vencer o problema que a imunologia se propôs resolver em sua criação: a produção de novas vacinas e novos métodos de tratamento. Os imunologistas, em geral, assim como a sociedade que financia suas pesquisas, permanecem convencidos de que a vacinação é o objetivo central no controle das doenças infecciosas. Mais de um século de repetidos insucessos em produzir vacinas eficazes pela injeção de inumeráveis preparações antigênicas não foram suficientes para sugerir uma mudança de atitude. Aqui e ali surgem exemplos de vacinas efetivas, como as antipoliomielite, que podem levar à erradicação completa da doença do planeta (Nature, 1976), como ocorreu com a varíola (Henderson, 1976).

Essa insistência em vacinar deriva principal mente da crença de que o corpo, de alguma forma, reconhece materiais estranhos e organiza suas defesas em resposta a esse reconhecimento. É surpreendente constatar quanto do conhecimento imunológi co estabelecido tem sido dominado por crenças não desafiadas e mesmo não examinadas.

\section{Referências}

CHU RCHLAND, P. S. \& SEJNOWSKY, T. J., 1988. Perspectives in computational neuroscience. Science, 242:741-745.

CHURCHLAND, P. S. \& SEJ NOWSKY, T. J., 1992. The Computational Brain. Cambridge: MIT Press.

DARWIN, C., 1979. A Origem das Espécies. São Paulo: Hermes Editora.

DICKLER, H. B. \& COLLIER, E., 1996. Vaccines: new approaches and concepts. Symposium synopsis. Journal of Allergy and Clinical Immunology, 97: 896-906.

NATURE, 1995. End of the road for poliomyelitis? Nature, 374:663.

HENDERSON, D. A., 1976. The erradication of smallpox. Scientific American, 235:25- 33.

JERNE, N. K., 1967. Antibodies and learning: selection versus instruction. In: The Neurosciences: A Study Program (G. C. Quarton, T. Melnechuck \& F. O. Schmitt, eds.), pp. 200-205, New York: The Rockefeller University Press.

KIPLE, K. F., 1993. The Cambridge World History of Human Disease Cambridge: Cambridge University Press.

KOHLER, W., 1925. The Mentality of Apes. New York: Humanities Press.

MAGRO, C.; GRACIANO, M. \& N. VAZ, 1997. Humberto Maturana: Ontol ogia da Realidade. Belo Horizonte: Editora UFM G.

MATURANA, H. R. \& VARELA, F. J., 1980. Autopoiesis and Cognition: The Realization of the Living. Reidel: Dordrecht.
MATURANA, H. R., 1988. Reality: the search for objectivity or the quest for the compelling argument. Irish Journal of Psychology, 9:25-82.

MATURANA, H., 1993. Prefácio. In: Guia Incompleto de Imunobiologia, Imunologia como seo Organismo Importasse(N. Vaz, \&A. M. C. Faria, orgs.), pp. I-II, Belo Horizonte: Coopmed.

MCCULLOCH, W. S. \& PITTS, W. H., 1965. A logical calculus of the ideas immanent in nervous activity. In: Embodiments of Mind (W. S. McCulloch, ed.), pp. 19-39, Cambridge: MIT Press.

MCCULLOCH, W. S., 1965. What is in the brain that ink may character? In: Embodi ments of Mind (W. S. McCulloch, org.), pp. 387-398, Cambridge: MIT Press.

McKEOW, T., 1988. The Origin of Human Diseases. New York: Blackwell.

REDDY, M.J. M., 1979. The conduit metaphor - a case of frame conflict in our language about language. In: Metaphor and Thought (A. Ortony, ed.), pp. 284-291, Cambridge: Cambridge University Press.

VON BEHRING, E. \& KITASATO, S., 1961. The mechanism of immunity in animals to diphteria and tetanos. In: Milestones in Microbiology (T. Brock, org.), pp. 138-140, Washington: American Association of Microbiology.

YOUNG, R. M., 1985. Darwin's Metaphor. Nature's Place in Victorian Culture. Cambridge: Cambridge University Press. 